\title{
Selective arabinose extraction from Pinus sp. sawdust by two-step soft acid hydrolysis
}

\author{
Carmen Bravo, Diego Garcés, Laura Faba, Herminio Sastre, Salvador Ordóñez* \\ Department of Chemical and Environmental Engineering, Faculty of Chemistry, University of Oviedo, Julián Clavería s/n, 33006 Oviedo, Spain
}

\section{A R T I C L E I N F O}

\section{Keywords:}

Hemicellulose

Acid treatment

Sawdust

Pentose

Green-process

\begin{abstract}
A B S T R A C T
Acid hydrolysis of Pinus sp. sawdust is optimized in this work in order to selectively recover arabinose from the hemicellulose fraction by an environmental-friendly process (reactions at atmospheric pressure and mild conditions and using dilute $\mathrm{HCl}$ as catalyst). The influence of temperature, $\mathrm{HCl}$ concentration and reaction time was studied in the first experiments considering one step hydrolysis. One step hydrolysis was studied at different conditions, being the best results obtained at $65^{\circ} \mathrm{C}$ for $18 \mathrm{~h}$ with $3 \%$ of $\mathrm{HCl}$, with more than $3.8 \mathrm{~g} / \mathrm{L}$ of arabinose in the liquid phase. This value corresponds to more than $47.5 \%$ of recovery of the arabinose present in the original sawdust and a selectivity of a $52 \%$ in the liquid phase (hydrolysis of other hemicellulosic sugars). In a second approach, a two steps process was considered in order to maximize the arabinose recovery. The optimum results were obtained combining a first cycle at $65{ }^{\circ} \mathrm{C}$ with a second one at $80{ }^{\circ} \mathrm{C}$. More than $54 \%$ of the initial arabinose was recovered in the liquid phase as monomers. This percentage increases to $100 \%$ if the oligomers are also considering (no arabinose detected in the solid phase after the treatment). At these conditions, more than $56 \%$ of the global hemicellulose sugars were removed from the solid phase, without having a relevant degradation of glucose (pentose selectivity in liquid phase is higher than $88 \%$, corresponding the resto mainly to hemicellulosic glucose).
\end{abstract}

\section{Introduction}

Lignocellulosic biomass is considered nowadays as the most promising alternative to fossil resources, not only to produce fuels and energy but also to obtain many different chemical products (Chin et al., 2013; Ghaffar et al., 2015; Faba et al., 2015). For the last point, a correct isolation of the different lignocellulosic fractions - lignin $(\sim 30 \%)$, cellulose $(\sim 40 \%)$ and hemicellulose $(\sim 30 \%)-$ is required (Menon and Rao, 2012). Lignin is a very complex aromatic fraction with high industrial value for the food and pharmaceutical industries. Cellulose is a crystalline homopolymer of glucose, typical raw material for the paper industry. Besides, new uses have been reported for these two fractions during the last few years, being considered the highest industrial valuable fractions of biomass (Gallezot 2012; Ragauskas et al., 2014; Deuss et al., 2014). Hemicellulose is a non-crystalline heteropolymer of different sugars, being the glucose, xylose and the arabinose the most important ones (Saha, 2003). Arabinose is a five carbon sugar, one of the main monomers in the hemicellulose of softwoods. It can be used as a non-caloric sweetener, dietary fiber, in flavors and as an intermediate for the synthesis of different drugs, mainly related to human diabetes, bacteriological diagnostics, anti- virus, production of vitamin B2 (Aguedo et al., 2013; Jiang et al., 2015). Despite of these important uses, arabinose commercial production is still nowadays a complex and expensive process consisting of acid hydrolysis of Arabic gum or other raw materials followed by multiple procedures of purification (Cheng et al., 2011), so the development of an alternative and easier process (starting, for example, from a low-value raw material such as the hemicellulose) would be very interesting.

Nowadays, there are several alternatives proposed to separate cellulosic and hemicellulosic polymers from the lignin and obtain the corresponding monomers by a partial degradation of the polymeric structure. The acid hydrolysis using sulfuric acid is the most common one (Alonso et al., 2010; Mäki-Arvela et al., 2011). Other methods developed for this purpose are hot water and alkaline treatments, AFEX, steam explosion, pyrolysis, COSLIF and ionic liquids (Capolupo and Faraco, 2016). However, the reaction conditions are so harsh that these processes cannot be considered as green-processes and sugars are easily dehydrated and transformed to small molecular weight degradation products (Klinke et al., 2004). Concerning to the acid hydrolysis, most of the previous literature suggests the $\mathrm{H}_{2} \mathrm{SO}_{4}$ as catalyst for this reaction, concluding that the complete sugar hydrolysis (complete but

\footnotetext{
* Corresponding author.

E-mail address: sordonez@uniovi.es (S. Ordóñez).
} 
not selective) is directly related to a good combination of temperature and acidity, in such a way that optimum results can be obtained after few minutes working at low temperature $\left(<50{ }^{\circ} \mathrm{C}\right)$ using concentrated acid $(30-70 \%)$ or using dilute acid $(<1 \%)$ at high temperatures $\left(>200{ }^{\circ} \mathrm{C}\right.$ ) (Rinaldi and Schüth, 2009; Kim and Mazza, 2008; Dong et al., 2016). Acid hydrolysis conditions could be modified, working at mild temperature with dilute acid and controlling the reaction time, in order to selectively hydrolyze the hemicellulose fraction without breaking the strong bonds between glucose monomers in the cellulose. This procedure balances the autohydrolysis and hydrolysis of biomass.

The particular properties of each wood can affect the results obtained with this pretreatment. In this work, sawdust of different pinewoods, all of them included in the Pinus sp. genus (mainly Pinus pinaster) is used as raw material. Pinus sp. is a softwood species, very common in woods of the north of Spain, with high value in the timber and wood industry. According to the literature, Pinus sp. is typically composed of $37.1-40 \%$ of cellulose, $28.3-28.5 \%$ of hemicellulose and $27.2-27.9 \%$ of lignin; with more than $10 \%$ of arabinose, being this percentage among the highest in woody species (Evtuguin and Neto, 2007; Mäki-Arvela et al., 2011). The manufacturing of Pinus sp. generates a high amount of sawdust, considered nowadays as a waste. The few references about the use of this material are focused in the pretreatment of this wood by the Organosolv process (BallinaCasarrubias et al., 2015), using soft acid media at high temperatures (Rivas et al., 2016) or even microbiological systems (Barbosa et al., 1992) whereas, to the best of our knowledge, there are not systematic studies about the soft hydrolysis at low temperatures of this sawdust. Hardwood hemicellulose is generally easier to hydrolyze than softwood hemicellulose (Marzialetti et al., 2008), so different parameters must be optimized in order to obtain an effective hydrolysis of this type of sawdust.

The aim of this work is to identify the reaction conditions that allow obtaining the maximum hemicellulose extraction, with main focus on recovering the arabinose in the liquid phase without altering the cellulose fraction (different temperatures, acid concentration, and number of cycles). We propose the use of $\mathrm{HCl}$ as homogeneous catalyst because its ecotoxicity is considerably lower than the toxicity of $\mathrm{H}_{2} \mathrm{SO}_{4}$, with values of 25 and $10 \mathrm{mg} / \mathrm{L}$, respectively (values published in their MSDS files).

\section{Materials and methods}

\subsection{Raw material}

Pinus sawdust was supplied by a local sawmill (Maderas Prieto, Asturias, Spain). The sawdust was air-dried and maintained in sealed plastic bags. The particle size distribution of this sawdust was analyzed using a Mastersizer S long bench equipment (Malvern Instruments, Ltd.) obtaining a pseudo-Gaussian distribution with an average diameter of $629.7 \pm 12 \mu \mathrm{m}$.

\subsection{Reaction conditions}

The hydrolysis was carried out in a $1 \mathrm{~L}$ double-walled, thermostatically temperature controlled, glass reactor. $50 \mathrm{~g}$ of wood sawdust was added to $500 \mathrm{~mL}$ of water (1:10 ratio). The resulting mixture was stirred at $500 \mathrm{rpm}$ until it reaches the reaction temperature (from 60 to $80{ }^{\circ} \mathrm{C}$ as function of the reaction). The hydrochloric acid was then introduced in the reactor (ranging $\mathrm{HCl}$ concentrations from 1 to $3 \%$ ), considering this moment as the starting point of the hydrolysis. Liquid samples are collected for 4 or $18 \mathrm{~h}$, neutralized with $\mathrm{CaCO}_{3}$ and filtered ( $0.45 \mu \mathrm{m}$ pore size).

The harshness of the dilute acid pretreatment conditions was quantified by the combined severity factor (CSF), a parameter firstly introduced by Chum et al. (1999) that relates the harshness to the reaction time $(\mathrm{t}, \mathrm{min})$, the temperature $\left(\mathrm{T},{ }^{\circ} \mathrm{C}\right)$ and $\mathrm{pH}$ as function of the following equation:

$C S F=\log \left[t \cdot \exp \left(\frac{T-100^{\circ} C}{14.7}\right)\right]-p H$

\subsection{Characterization of liquids}

Liquid phase concentration of the different sugars was analyzed by high performance liquid chromatograph (HPLC) in an Agilent 1200, using a Hi-Plex H column and a refractive index detector. Milli-Q water was used as mobile phase, with a flow rate of $0.6 \mathrm{~mL} / \mathrm{min}$. Column and detector temperatures were fixed at $50{ }^{\circ} \mathrm{C}$. In order to obtain quantitative data, commercial samples of $\mathrm{D}(+)$-glucose (Panreac, ACS quality), $\mathrm{D}(+)$-galactose (Panreac, $\geq 98 \%$ ), $\mathrm{L}(+)$-arabinose (Panreac, $\geq 98 \%$ ), $\mathrm{D}$ $(+)$-xylose (Fluka, $\geq 99 \%$ ) and $\mathrm{D}(+)$ )-manose (Sigma Aldrich, $\geq 99 \%$ ) were used.

\subsection{Characterization of solids}

The chemical composition of the solid phase (structural carbohydrates and lignin biomass) was determined following the Standard Biomass Analytical Methods provided by the National renewable Energy Laboratory (NREL) of the American Department of Energy. According to this procedure, $300 \mathrm{mg}$ of sample was hydrolyzed in strong conditions with $3 \mathrm{~mL}$ of $\mathrm{H}_{2} \mathrm{SO}_{4}$ at $72 \%$ for $1 \mathrm{~h}$ at $30{ }^{\circ} \mathrm{C}$ in a water bath under stirring. Hydrolyzed sample was diluted with $84 \mathrm{~mL}$ of deionized water and the degradation continues in an autoclave at $121^{\circ} \mathrm{C}$ for $21 \mathrm{~min}$ with the aim to guarantee the complete hydrolysis. Resulting liquid was filtered, neutralized and analyzed by HPLC with a refractive index detector to quantify the carbohydrates. Acid lignin content is obtained by analyzing same sample with HPLC using a UV-vis spectrometer. Details of both procedures are reported in the literature (Sluiter et al., 2008).

Cellulose content was determined by discounting from the whole glucose the fraction that takes part of glucomannans. According to the literature, the mannose (Man) to glucose (Glu) ratio in the pine hemicellulose is 4.15 (Yoon et al., 2008). No other monomers were detected in any analysis. Consequently, the glucose from cellulose (named Mono-C) and hemicellulose sugars (named Mono-H) in the original pine sawdust were calculated using the following equations:

Mono $-C=G l u-\frac{\text { Man }}{4.15}$

Mono $-H=A r a+X y l+G a l+M a n+\frac{M a n}{4.15}$

The crystallographic structure of the solids (both fresh and after the hydrolysis) were determined by X-ray diffraction (XRD) using a Philips X'Pert Pro diffractometer, working with the $\mathrm{Cu}-\mathrm{K} \alpha$ line $(\lambda=0.154 \mathrm{~nm})$ in the $2 \theta$ range of $5-30^{\circ}$ at a scanning rate of $0.02^{\circ} / \mathrm{min}$. The crystalline structures were determined by comparison with the polymeric databases of ICDD PDF-2, PAN ICSD and PAN COD. The crystallinity index was calculated by the methodology proposed by Thygesen and coworkers (Thygessen et al., 2005) based on the Segal equation, where $I_{c}$ is the intensity of the maximum crystalline peak and $\mathrm{I}_{\mathrm{a}}$ is the minimum intensity between two crystalline peaks:

$C I=\frac{I_{c}-I_{a}}{I_{c}}$

The solid morphology was analyzed by scanning emission microscopy (SEM) using a JEOL JSM-6100 instrument. Aluminum support was used and samples were pretreated by sputtering with gold for $40 \mathrm{~s}$. Micrographs showed correspond to 7500 magnifications.

The analyses of the solid phase were carried out to characterize both, the raw material and the remaining solids obtained after each reaction. 
Table 1

Contents on cellulose, hemicellulose, lignin and ash of the fresh sawdust and the solids obtained after each hydrolytic treatment.

\begin{tabular}{|c|c|c|c|c|c|c|}
\hline \multirow[t]{2}{*}{ Entry } & \multirow[t]{2}{*}{ Sample } & \multirow[t]{2}{*}{ Moisture } & \multicolumn{4}{|c|}{ Sawdust division (dry basis, \%) } \\
\hline & & & Cellulose & Hemicellulose & Lignin & Ash \\
\hline 1 & Original sawdust & 9.6 & 40.2 & 31.4 & 27.2 & 1.1 \\
\hline 2 & $60{ }^{\circ} \mathrm{C}, 3 \%, 4 \mathrm{~h}$ & n.m. & 42.3 & 28.4 & 36.0 & 1.5 \\
\hline 3 & $65^{\circ} \mathrm{C}, 3 \%, 4 \mathrm{~h}$ & n.m. & 42.5 & 26.2 & 37.2 & 1.6 \\
\hline 4 & $70{ }^{\circ} \mathrm{C}, 3 \%, 4 \mathrm{~h}$ & n.m. & 42.6 & 25.4 & 38.1 & 1.6 \\
\hline 5 & $80{ }^{\circ} \mathrm{C}, 3 \%, 4 \mathrm{~h}$ & n.m. & 43.7 & 21.3 & 39.1 & 1.8 \\
\hline 6 & $65^{\circ} \mathrm{C}, 1 \%, 18 \mathrm{~h}$ & n.m. & 42.9 & 25.4 & 28.9 & 2.7 \\
\hline 7 & $65^{\circ} \mathrm{C}, 2 \%, 18 \mathrm{~h}$ & n.m. & 43.4 & 22.4 & 31.1 & 2.8 \\
\hline 8 & $65^{\circ} \mathrm{C}, 3 \%, 18 \mathrm{~h}$ & n.m. & 46.2 & 18.5 & 32.1 & 3.0 \\
\hline 9 & $\begin{array}{l}\text { 2nd c. } 60^{\circ} \mathrm{C}, 3 \% \text {, } \\
4 \mathrm{~h}\end{array}$ & n.m. & 40.9 & 20.5 & 33.9 & 1.7 \\
\hline 10 & $\begin{array}{l}\text { 2nd c. } 70^{\circ} \mathrm{C}, 3 \% \text {, } \\
4 \mathrm{~h}\end{array}$ & n.m. & 40.6 & 17.8 & 37.8 & 2.9 \\
\hline 11 & $\begin{array}{l}\text { 2nd c. } 80^{\circ} \mathrm{C}, 3 \% \text {, } \\
4 \mathrm{~h}\end{array}$ & n.m. & 37.8 & 13.9 & 42.5 & 3.1 \\
\hline
\end{tabular}

n.m. $=$ not measured.

\section{Results and discussion}

\subsection{Sawdust characterization}

As it is detailed in Table 1, the pine sawdust presents the typical chemical composition of softwood, with high content of insoluble lignin (17.9\%) and hexoses (55.9\%). These results were obtained considering the dry wood, after evaporating the water ( $9.4 \%$ of moisture). The ash content is $1.1 \%$. According to the previous equations, the monomeric sugar distribution corresponds to $40.2 \%$ and $31.4 \%$ of Mono-C and Mono- $\mathrm{H}$, respectively. An individual analyses of the hemicellulose fraction conclude that this fraction corresponds to $7.7 \%$ of xylose, $8 \%$ of arabinose; $10.8 \%$ of manose; $2.3 \%$ of galactose and $2.6 \%$ of glucose, being the two first sugars the main responsible of the inhibition of yeasts activity during sugar fermentation. These values are congruent the XRD spectrum observed in Fig. 1(a), that corresponds with a crystallinity index of $46.6 \%$. This index is calculated from the height ratio between the intensity of the crystalline peak, $\mathrm{I}_{002}-\mathrm{I}_{\mathrm{am}}$, (at $2 \theta=22.6^{\circ}$ and $18^{\circ}$, respectively) and total intensity $\left(\mathrm{I}_{002}\right)$. The physical structure of the untreated sawdust sample was studied by SEM, being the most representative micrograph plotted in Fig. 1(b). At low resolution (60 magnifications), a clear fibrous structure with high and random porosity is observed. Increasing the magnifications to 7500 , the cellulose well-defined structure is clearly detected, without evidences of lignin in the external structure, usually observed as spheres (Sannigrahi et al., 2011).

\subsection{Influence of the hydrolysis temperature on the products distribution}

The first step of the proposed process implies a hydrolysis of the pine sawdust using dilute hydrochloric acid as homogeneous catalyst. Previous references in the literature suggest this acid when reaction is carried out at high temperatures, from $100{ }^{\circ} \mathrm{C}$ to $190{ }^{\circ} \mathrm{C}$ with $0.5 \%$ of $\mathrm{HCl}$, recovering almost $90 \%$ of the initial sugars after 20 min (Ertas et al., 2014). In our first tests, the $\mathrm{HCl}$ concentration is increased to $3 \%$ and four mild temperatures were studied (from 60 to $80^{\circ} \mathrm{C}$ ), increasing the reaction time to $4 \mathrm{~h}$ with the aim to compensate the predictable lower hydrolysis rate when working at low temperatures. Considering the reaction conditions, these experiments correspond to CSF values of $1.20\left(60{ }^{\circ} \mathrm{C}\right), 1.35\left(65^{\circ} \mathrm{C}\right), 1.5\left(70^{\circ} \mathrm{C}\right)$ and $1.8\left(80^{\circ} \mathrm{C}\right)$. These values are slightly lower than those suggested in the literature as the optimum for the complete sugar hydrolysis (hemicellulose and cellulose) (Gaur et al., 2016; Gonzales et al., 2016); so it is expected that hemicellulose would be the most affected fraction, whereas cellulose would be almost unaltered. Initial experiments at same temperatures without any $\mathrm{HCl}$ in the reaction medium confirm the absence of any non-catalytic reaction (autohydrolysis), with no monomers detected by HPLC after $4 \mathrm{~h}$ at same reaction conditions. The sawdust autohydrolysis has been previously reported but at temperatures higher than $100{ }^{\circ} \mathrm{C}$, usually close to $200{ }^{\circ} \mathrm{C}$ (Sidiras et al., 2011; Cara et al., 2012).

The temporal evolutions of arabinose (pentose selected as the main product because of its high concentration), the other hemicellulosic sugars (xylose, mannose and galactose considered together) and glucose are shown in Fig. 2. The arabinose evolution (Fig. 2a) has a continuous increasing trend, reaching concentrations higher than $3.2 \mathrm{~g} / \mathrm{L}$ of this pentose in the liquid when temperature is fixed at $80^{\circ} \mathrm{C}$. This value corresponds to the removal of $43.7 \%$ of initial arabinose in the sawdust. Besides that lower conversions are obtained at lower temperatures, no equilibrium state is reached in any test, suggesting that longer reaction times could improve these values. Profiles obtained at 65 and $70{ }^{\circ} \mathrm{C}$ are quite similar, with final values of 1.4 and $1.6 \mathrm{~g} / \mathrm{L}$ of arabinose in liquid phase, respectively. These values correspond to 17.5 and $20 \%$ of global arabinose recovery, respectively.

Concerning to the other sugars of the hemicellulosic fraction (Fig. 2b), results obtained at temperatures lower than $70^{\circ} \mathrm{C}$ are very similar, with less than $0.7 \mathrm{~g} / \mathrm{L}$ after $4 \mathrm{~h}$ of reaction in all the cases. On the contrary, the hydrolysis of the whole hemicellulose is very relevant at the highest temperature, with almost $18 \%$ of the initial galactose, xylose and mannose recovered in the liquid phase. These results suggest that $20 \%$ of the arabinose in the pine sawdust is located in the external structure of the hemicellulose polymers, whereas the other $80 \%$ takes part of the internal and more complex hemicellulosic fraction. As consequence, only the first $20 \%$ can be selectively hydrolyzed at these conditions. When this percentage is already hydrolyzed, the acidity is enough to attack the other sugar bonds and the selectivity of the

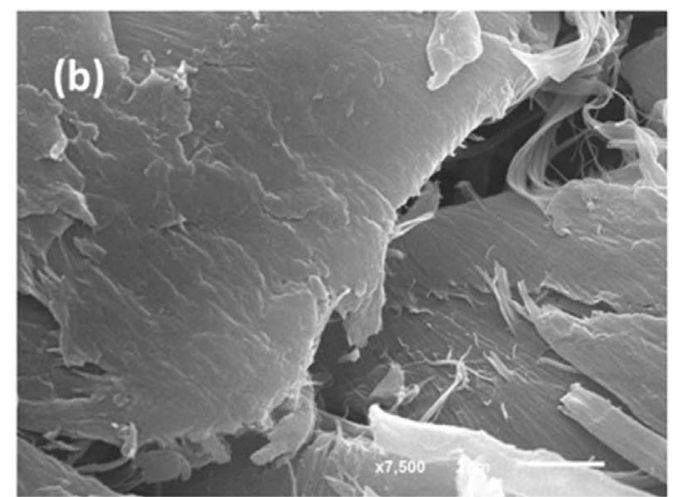

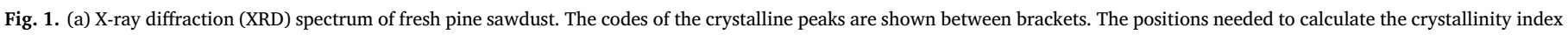

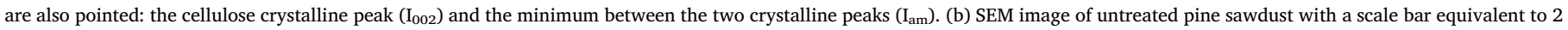
$\mu \mathrm{m}$. 


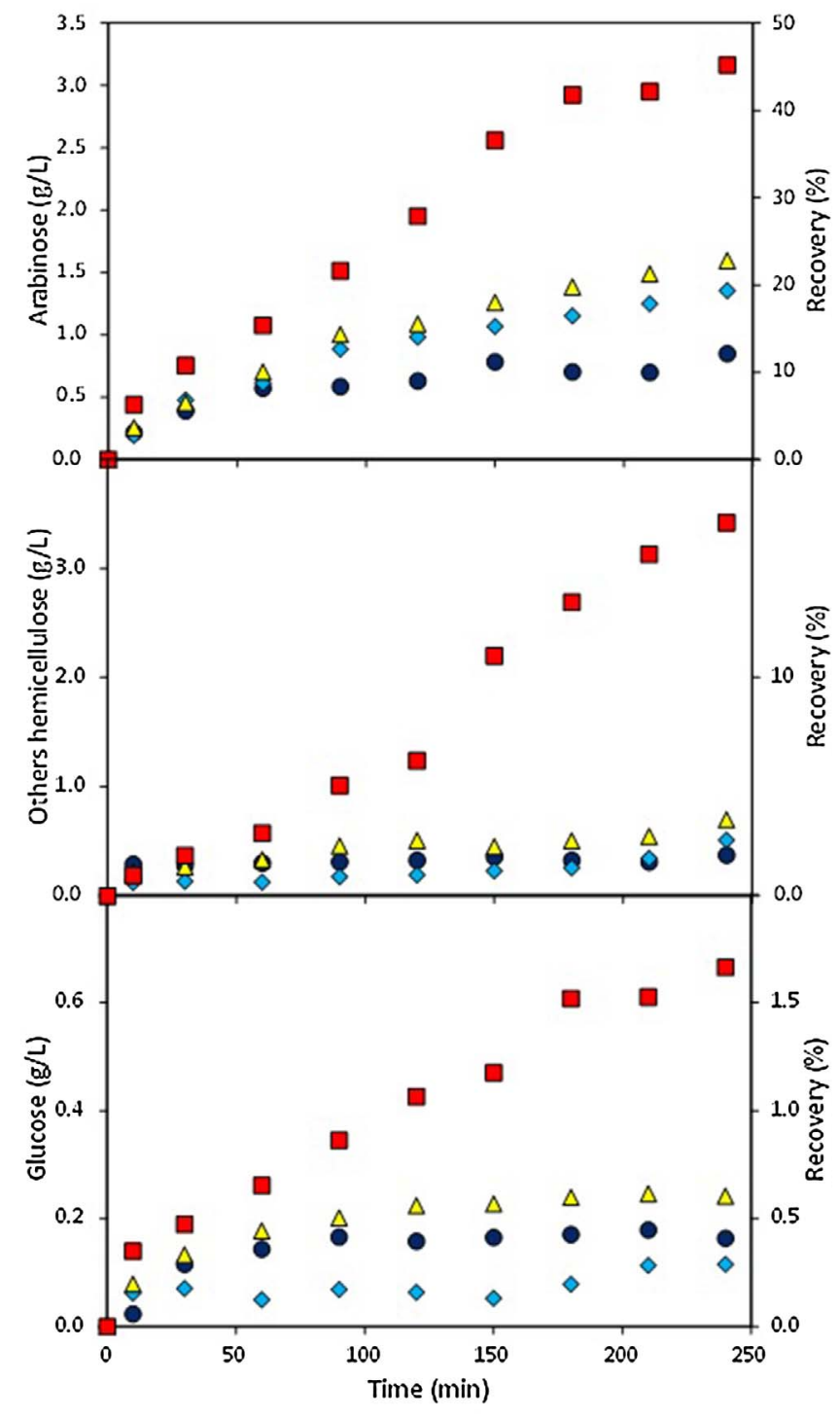

Fig. 2. Temporal evolution of the different monomeric sugars detected in the hydrolysis of pine sawdust catalyzed by $3 \%$ of $\mathrm{HCl}$. Results correspond to reaction at: $(\bullet) 60^{\circ} \mathrm{C}$; ( $\left.\diamond\right)$ $65{ }^{\circ} \mathrm{C}$; ( ) $70{ }^{\circ} \mathrm{C}$ and $(\square) 80^{\circ} \mathrm{C}$.

reaction decreases quickly.

Similar behavior is observed for glucose (Fig. 2c), although less markedly. In this case, less than $1 \%$ of the whole glucose is obtained in the liquid phase, being much more relevant at $80{ }^{\circ} \mathrm{C}$. According to sawdust composition summarized in Table 1 , only $2.6 \%$ of the glucose is part of the hemicellulosic fraction (mainly as glucomannan polymers in this kind of woods). Then, the glucose percentage in the liquid phase is congruent with the selective degradation of the hemicellulose, without modifying the most of the glucose of the cellulose fraction. As conclusion, $66 \%$ of the glucose from hemicellulose are obtained in the liquid phase at $80{ }^{\circ} \mathrm{C}$, whereas this value decreases to $13.7 \%$ at $60{ }^{\circ} \mathrm{C}$ (higher selectivity to arabinose).

No aromatics were detected in the liquid analyses, suggesting that lignin is unaltered after the reaction. In the same way, no furfural or 5hydroxymethylfurfural (5-HMF) were detected, discarding the degradation of sugar monomers. A relevant concentration in sugar oligomers, mainly dimmers, was detected in all the cases, reaching final values of $1.62,3.12,2.70$ and $2.99 \mathrm{~g} / \mathrm{L}$ at $60,65,70$ and $80^{\circ} \mathrm{C}$, respectively. All these compounds were considered together, being their temporal evolution included in the Supplementary information (Fig. S1). At short reaction times, the concentration of these oligomers is directly proportional to the reaction temperature. After one-two hours, profiles suggest an equilibrium situation in which the partial hydrolysis of hemicellulose is in equilibrium with the complete hydrolysis of these oligomers, yielding the sugars. Despite the temperature, the oligomer concentrations indicate that the hydrolysis is not complete after $4 \mathrm{~h}$, with a significant amount of intermediates. Considering all the sugars detected in the liquid phase (monomers and oligomers together), the final concentrations where $3,5.1,5.3$ and $10.1 \mathrm{~g} / \mathrm{L}$ (in increasing temperature order), which correspond to values of initial hemicellulose recovered of $9.6,16.25,16.7$ and $32.1 \%$, at $60,65,70$ and $80^{\circ} \mathrm{C}$, respectively. On the other hand, small amounts of acetic and formic acid were also detected (never reaching $5 \%$ of the total concentration), suggesting the presence of acetyl groups in terminal positions of hemicellulose polymers. The presence of these acids after these pretreatments has been previously reported in the literature (Moniz et al., 2014). Considering the weak character of these acids and the initial $\mathrm{pH}$ of the reaction (0.09), these acids do not play any relevant role in the process.

Considering that the hemicellulose hydrolysis is not the only aim of this work but also to get higher arabinose selectivities, results obtained must be analyzed in terms to selectivity in order to set the best operation conditions. The final distribution of the main products after $4 \mathrm{~h}$ of reaction is plotted in Fig. S2 in terms of selectivity. As it could be expected, the whole selectivity to pentoses is always over $85 \%$, in good agreement with the soft character of this pretreatment. The highest arabinose selectivity is reached at $65{ }^{\circ} \mathrm{C}$, obtaining a liquid phase in which arabinose is almost $70 \%$ of the whole sugars, with more than $94 \%$ of pentoses at these conditions. This value corresponds to $20 \%$ of the arabinose in the initial pine sawdust recovered after $4 \mathrm{~h}$ and profiles suggest that this value can be improved with longer times or by introducing a second step at higher temperature in which the reaction conditions make easier this hydrolysis.

Solids obtained after all the reactions were recovered by filtration, dried in the oven at $105{ }^{\circ} \mathrm{C}$ and analyzed in order to determine the evolution of their structure. XRD analyses, shown in Fig. 3, are congruent with results in the liquid phase, observing a slight and progressive increase in the crystallinity. This fact is justified by the selective hydrolysis of hemicellulose phase, keeping unaltered the cellulose. These spectra correspond to crystallinity index (CI) values of $51.8,52.7,53.6$ and $54.2 \%$ after reaction at $60,65,70$ and $80^{\circ} \mathrm{C}$, respectively. NREL procedure was also applied to these samples, obtaining the structural sugar fractionation summarized in Table 1 (entries 2-4). The decrease in the hemicellulose fraction is the main conclusion of these analyses, with the subsequent increase in the other fractions, mainly the lignin one. This result is congruent with the absence of aromatic compounds in the liquid phase, and suggests that

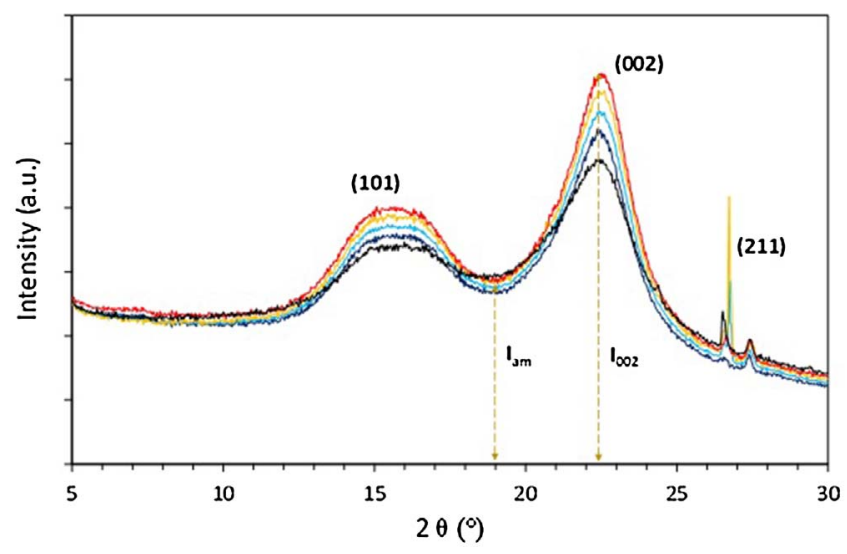

Fig. 3. X-ray diffraction (XRD) spectra of fresh pine sawdust (black) and after the hydrolysis at different temperatures: $60{ }^{\circ} \mathrm{C}$ (dark blue); $65{ }^{\circ} \mathrm{C}$ (light blue); $70{ }^{\circ} \mathrm{C}$ (yellow) and $80^{\circ} \mathrm{C}$ (red). (For interpretation of the references to colour in this figure legend, the reader is referred to the web version of this article.) 
this pretreatment at these conditions is selective to sugars. Considering these compositions, with all the main and side products in the liquid phase, final carbon balances were always higher than $85 \%$ (88.4, 91.1, 86.4 and $95.5 \%$, in the temperature order). Analyzing the individual composition of the hemicellulose fraction (the remaining solids), less than $1.5 \%$ of arabinose was obtained in all the cases $(1.4,0.97,0.48$ and $0.36 \%$ ), indicating that these treatments are good alternatives to remove this sugar. However, the concentration of the other main pentose (xylose) is still relevant, with values higher than $2 \%$ in all the cases $(5.2,4.1,3.2$ and $2.1 \%)$.

The physical structure of the treated sawdust samples was studied by SEM, being the most representative micrographs plotted in Fig. S3. The high similarity among all the images corroborates that main structure of pine sawdust keeps almost unaltered during the treatment. At low resolution (60 magnifications), a clear fibrous structure with high and random porosity is observed. Increasing the magnifications to 7500 , the cellulose well-defined structure is clearly detected, observing fewer imperfections after treatment at highest temperatures (related to the hemicellulose), but with no evidences of strong degradation. According to the literature, the presence of discrete spherical balls or droplets on the surface would be the first sign of a too severe pretreatment in which hemicellulosic derivatives condense, obtaining different compounds generally called pseudo-lignin (Sannigrahi et al., 2011). These droplets were not detected in any of these micrographs.

\subsection{Influence of the $\mathrm{HCl}$ concentration in the arabinose selective hydrolysis}

Considering that acidity could promote other hydrolysis, and trying to prevent or minimize the hydrolysis of the other hemicellulosic sugars, data obtained with $3 \%$ of $\mathrm{HCl}$ were compared with results at lower acidity ( 1 and $2 \%$ of $\mathrm{HCl}$ ). These experiments were performed at $65^{\circ} \mathrm{C}$ during $18 \mathrm{~h}$. Temporal evolution of main products is plotted in Fig. 4, whereas Fig. S4 summarizes the final products distribution after these $18 \mathrm{~h}$ in terms of selectivities. Concerning to the arabinose, no significant differences in the profiles were observed among the different experiments, with similar tendencies and higher values at increasing acidity. However, the concentrations of the other sugars is almost negligible in the first $10 \mathrm{~h}$ reaction time in the experiments performed with 1 and $2 \%$ of $\mathrm{HCl}$, whereas these concentrations are significant working at $3 \% \mathrm{HCl}$. At $1 \%$ and $2 \%$ profiles are very similar, with a fast increase in these sugars concentrations during the last four hours and reaching similar values. Similar trends are obtained in the analyses of glucose, being even more evident the differences between $3 \%$ of $\mathrm{HCl}$ and softer conditions.

As to the final values, more than $52 \%$ of the initial arabinose is recovered after $18 \mathrm{~h}$ working with $3 \%$ of $\mathrm{HCl}$, with a final concentration of $3.81 \mathrm{~g} / \mathrm{L}$ of this sugar in the liquid phase; whereas less than $17 \%$ of the other hemicellulosic sugars were hydrolyzed, obtaining a final concentration lower than $0.5 \mathrm{~g} / \mathrm{L}$ of cellulose. These data correspond to an arabinose selectivity of $52 \%$, whereas all the hemicellulosic sugars correspond to almost $95 \%$ of the sugars in the liquid phase (Fig. S4). The selectivity to arabinose is improved when $\mathrm{HCl}$ concentration decreases, reaching the maximum value at $2 \%$ of $\mathrm{HCl}$, with $60 \%$. However, the final concentrations obtained at these conditions are considerably lower (1.8 and $3 \mathrm{~g} / \mathrm{L}$ with 1 and $2 \%$ of $\mathrm{HCl}$, respectively). As in previous cases, no aromatic compounds were detected in any of these experiments, suggesting that cellulose and lignin are unaltered after the treatment. On the other hand, the oligomer concentrations increase from 2.3 to $5.4 \mathrm{~g} / \mathrm{L}$ at increasing acidity. Taking into account that cellulose remains in the solid phase, these results indicate that 19.1, 28.6 and $41.3 \%$ of the initial hemicellulose (at 1, 2 and $3 \%$ of $\mathrm{HCl}$, respectively) is recovered in the liquid phase (as monomers or oligomers).

After $18 \mathrm{~h}$ of reaction, the solids were recovered by filtration, dried in an oven and analyzed following the NREL procedure and data obtained were added to Table 1 (entries 6-8). The increases in the

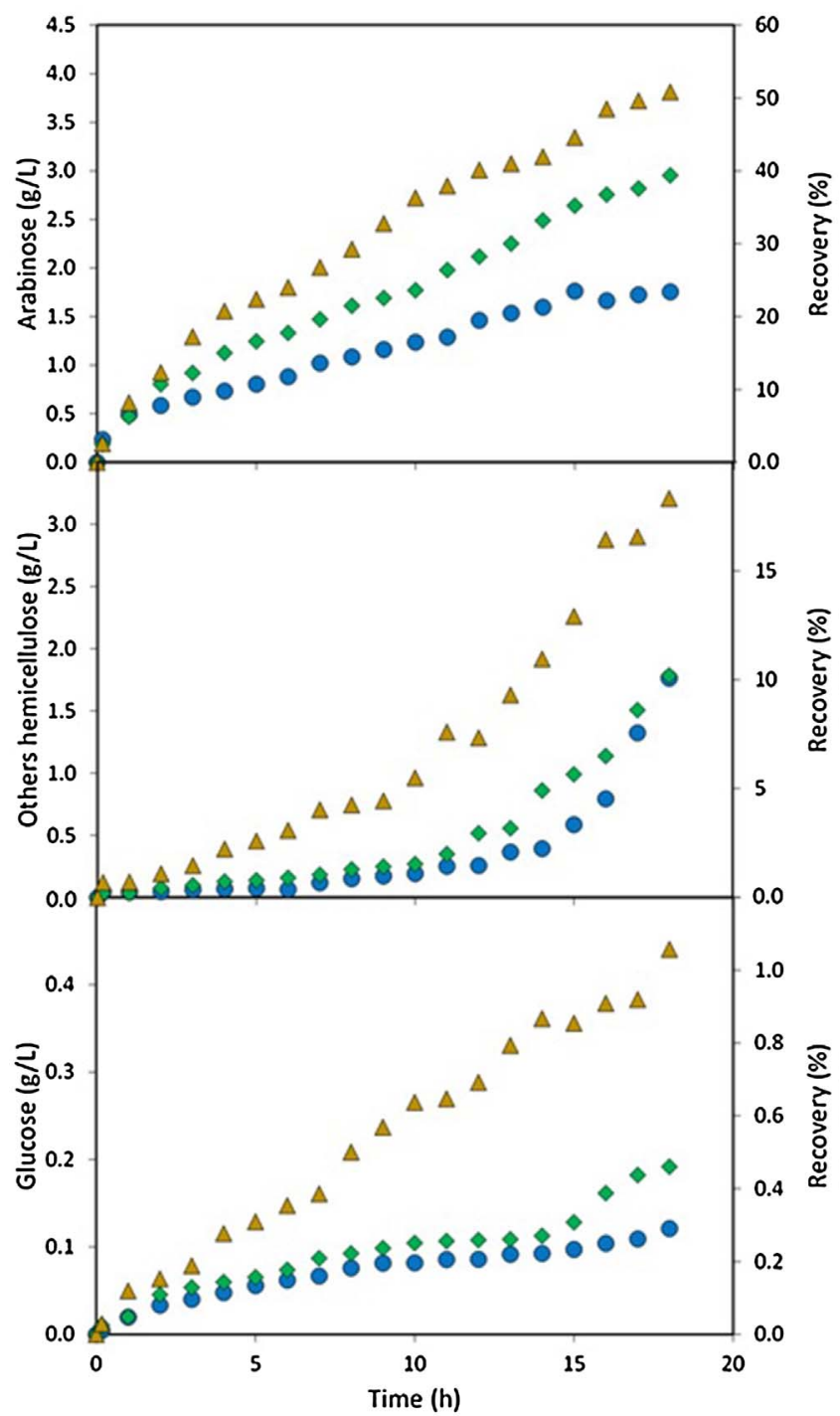

Fig. 4. Temporal evolution of the different monomeric sugars detected in the hydrolysis of pine sawdust at $65{ }^{\circ} \mathrm{C}$ as function of the $\mathrm{HCl}$ concentration. Symbols: $(\bullet) 1 \%$; (४) $2 \%$; ( ) $3 \%$.

lignin and glucose percentages (mainly in the lignin) are congruent with the fact that these fractions keep unaltered despite of the treatment and only the hemicellulose is attacked by the acid. Analyzing the individual composition of the hemicellulose fraction, less than $1 \%$ of arabinose was obtained in all the cases (0.97, 0.26 and $0 \%$ ), indicating that these treatments are good alternatives to remove this sugar. However, the concentration of the other main pentose (xylose) is still relevant, with values higher than $2 \%$ in all the cases. Considering these sugars remained in the solid phase as well as the oligomers and monomers in the liquid phase, the final carbon balance of results obtained were always higher than $92 \%$.

In parallel with previous experiments, solids were also analyzed by XRD and SEM, being the main results summarized in Figs. S5 and S6, respectively, of the supplementary information. As it could be expected, very similar profiles were obtained with both techniques. Concerning to the XRD, very similar profiles were obtained at 1 and $2 \%$ with less intensity in the case of $3 \%$. Results obtained correspond to a slight and successive increase in the crystallinity for the two main reactions (56.6 and $56.8 \%$ ) and a slight decrease to $54.8 \%$ in the reaction at $3 \%$. These values suggest that reaction at $3 \%$ slightly attack the cellulose fraction, whereas reactions at 1 and $2 \%$ only affect to the hemicellulose one. On the other hand, no evidences of pseudo-lignin were detected by SEM, 


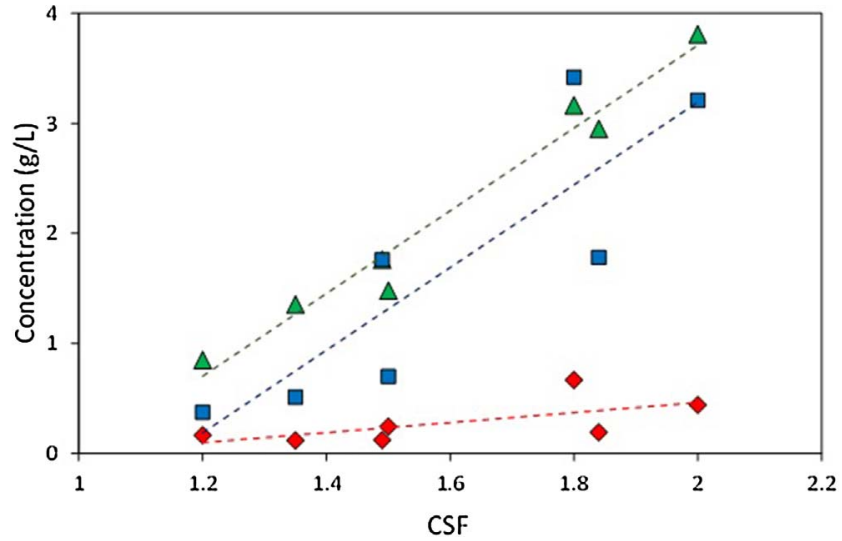

Fig. 5. Correlation between the coefficient of severity factor and the final sugar concentrations obtained by the hydrolysis of pine sawdust. Results corresponding to: $(\Delta)$ arabinose; $(\square)$ other pentoses and $(\diamond)$ glucose.

observing a higher degradation in the initial laminar structure after treatments at strongest conditions.

In order to analyze the influence of hydrolysis conditions globally (temperature, $\mathrm{pH}$ and time) in the results, the final concentration of arabinose, the other hemicellulosic sugars and glucose in the liquid phase as function of the CSF factor is plotted in Fig. 5. A linear trend is observed in the evolution of the arabinose, concluding that all the reaction parameters studied ( $\mathrm{pH}$, temperature and time) have a similar and positive effect in its hydrolysis. Different behaviors were obtained for the other sugars. Concerning to the other pentoses, data are adjusted also to a linear tendency with similar slope as the arabinose. However, there are relevant differences between similar CSF obtained by changing different parameters, in such a way that temperature seems to be the key parameter. Comparing similar CSF's, such as 1.49 and 1.5 or 1.8 and 1.84, a higher amount of these sugars was recovered at temperatures over $70{ }^{\circ} \mathrm{C}$, whereas similar CSF's obtained at lower temperatures by combining with lower acidity or longer times are not so effective. Finally, as to the glucose, the logical increasing tendency at increasing severe conditions was also observed, but with a significant lower slope, being congruent with the refractory character of the cellulose. In this case, the key role of the reaction temperature was also detected, being the relevance much lower than in the case of pentoses.

\subsection{Successive cycles at different temperatures}

Second alternative proposed consists on trying to improve the hemicellulose recovery (not only the selective arabinose) by combining the results obtained in a first cycle at $65{ }^{\circ} \mathrm{C}$ (the most selective one, shown in Fig. S2) with second cycles in which the solid (after filtered and dried) is subjected to a secondary hydrolytic step at different temperatures $\left(60,70\right.$ and $\left.80^{\circ} \mathrm{C}\right)$. The evolution of these second cycles is shown in Fig. 6. Similar trends than in the first cycle were obtained, with very similar profiles at 60 and $70{ }^{\circ} \mathrm{C}$ and significant differences in the case of the highest temperature tested. Considering that the selectivity to pentose sugars in the first cycle at $65{ }^{\circ} \mathrm{C}$ was higher than $94 \%$, the main objective of this second cycle is to increase the amount of sugars recovered trying to keep constant this selectivity. According to this premise, best results are obtained with the second cycle at $80{ }^{\circ} \mathrm{C}$, with almost $23 \%$ of hemicellulosic sugars recovered as monomers after the two cycles. This value increases significantly when the amount of oligomers is also considered, reaching a final hemicellulose removal of $53 \%$ (final oligomers concentrations of $6.49 \mathrm{~g} / \mathrm{L}$ at these conditions). Besides, more than $54 \%$ of the initial arabinose was recovered as monomers. The increasing tendency of profiles obtained at $80{ }^{\circ} \mathrm{C}$ suggests that longer times can increment this value to close to $100 \%$, whereas profiles at lower temperatures seem to reach a maximum and the stationary state at lower conversions (mainly in the case of

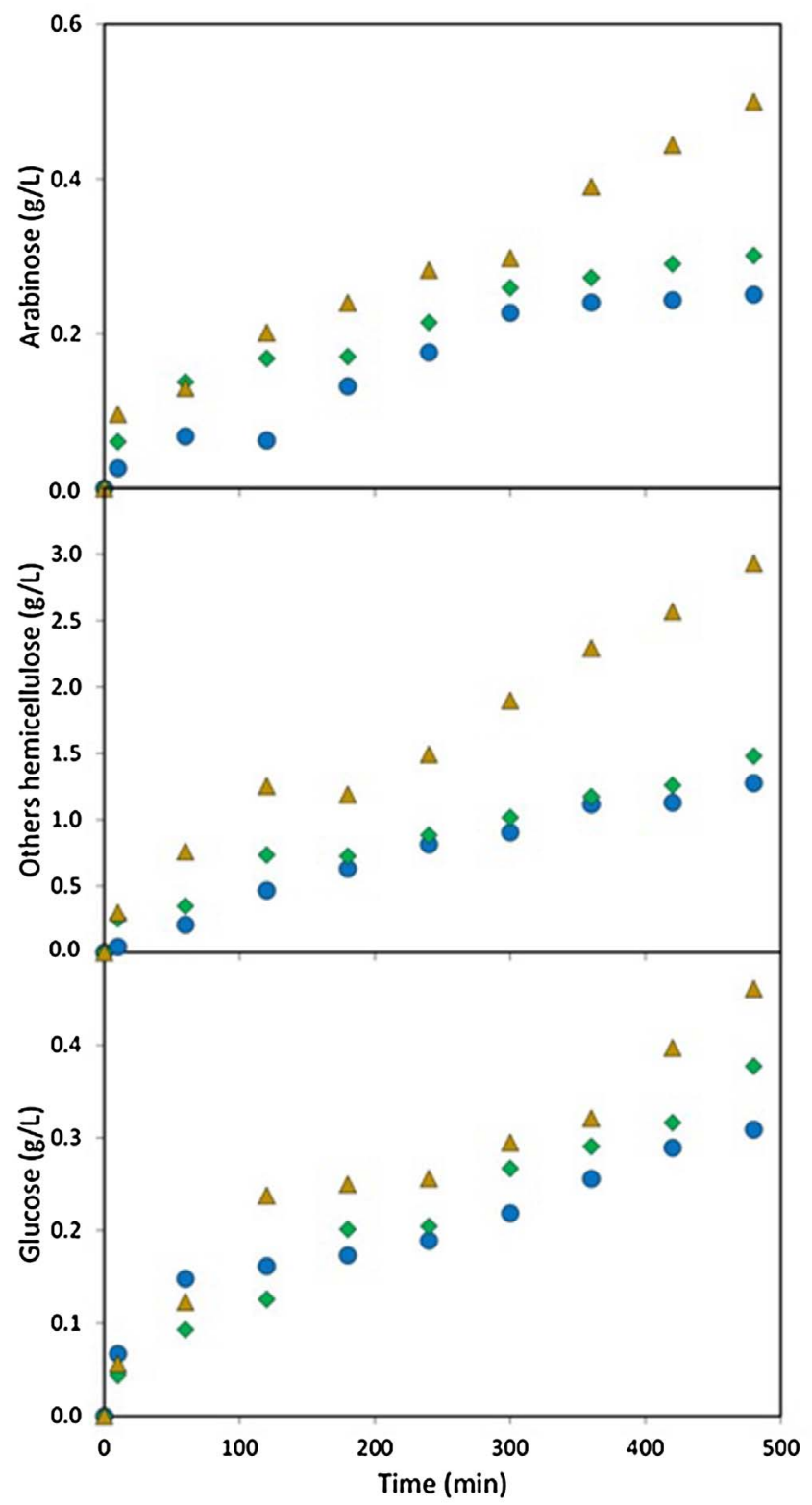

Fig. 6. Temporal evolution of the different monomeric sugars detected in the second cycle of hydrolysis catalyzed by $3 \%$ of $\mathrm{HCl}$ as function of the temperature. Symbols: (๑)

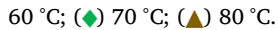

arabinose with removal ratios of 33 and $35 \%$ after the second cycle at 60 and $70^{\circ} \mathrm{C}$ ). On the contrary of the behavior in the first cycles, the evolution of the glucose in the liquid phase was very similar in all the cases, with differences lower than $0.1 \mathrm{~g} / \mathrm{L}$ between the lowest and the highest temperature tested. All these values correspond to the selectivities distributions showed in Fig. S7. In all the cases, the glucose selectivity was lower than $18 \%$, reaching global pentose selectivities of 83.2, 82.5 and $88.2 \%$, at increasing temperatures.

Concerning to the solids obtained after the treatments, the sawdust fractions are included in Table 1 (entries 9-11), highlighting the proportional increase of lignin and cellulose ones, and the subsequent decrease in the hemicellulose. Analyzing the individual sugar composition of this last fraction, no arabinose or xylose were detected after any second cycle, considering that this procedure is effective to remove the pentoses that can produce inhibition in fermentation reactions. As consequence, solids obtained after these two-cycle hydrolysis can be better transformed into bioethanol and the combination of 65 and $80{ }^{\circ} \mathrm{C}$ were chosen as the optimum configuration based on its higher conver- 
sion and hemicellulose removal. XRD and SEM analyses are reported in the supplementary information (Figs. S8 and S9) are congruent with results in the liquid phase, observing an increase in the crystallinity in experiments that only attack to the hemicellulose fraction (51.2 and $55.9 \%$ after treatments at 60 and $70{ }^{\circ} \mathrm{C}$ ) and a slight decrease to $52.8 \%$ after the treatment at highest temperature, in which the cellulose is also affected. SEM images also show the higher degradation of main structure at these conditions.

These results are slightly lower than other previously reported in the literature using stronger pretreatment conditions. For example, the $14.9 \%$ of arabinose final yield observed by $\mathrm{Yu}$ et al. These results cannot be directly compared because they are conditioned by the higher amount of arabinose in the raw material as well as the relevant hydrolysis of glucose because of the more severe conditions that reaches selectivities higher than 30\% (Yu et al., 2017). Other relevant results are summarized in the review of Peng et al., suggesting the arabinose separation by different extractions and precipitations (Peng et al., 2012). Despite that good results are reported, arabinose is obtained as a salt and not as monomers, and these salts must be treated before their direct upgrading. The higher selectivity and its recovery as monomer is the main advantage in comparison to other works related to the hydrolysis of similar type of woods but using more severe conditions (Ertas et al., 2014; Gaur et al., 2016; Gonzales et al., 2016; Sidiras et al., 2011)

\section{Conclusions}

The diluted-acid treatment of pine sp. sawdust has shown to be effective for the selective extraction of arabinose monomers from the hemicellulose fraction, keeping intact the lignin and cellulose fractions. As it was expected, higher hemicellulose hydrolysis was reached at highest temperatures $\left(80^{\circ} \mathrm{C}\right)$ with $9.57 \mathrm{~g} / \mathrm{L}$ of pentose monomers in the liquid phase after $4 \mathrm{~h}$. However, these conditions are too aggressive and a relevant amount of glucose was also detected (almost $1 \mathrm{~g} / \mathrm{L}$ ), suggesting that the cellulose fraction is also damaged. At softer temperatures $\left(65^{\circ} \mathrm{C}\right) 7 \mathrm{~g} / \mathrm{L}$ of pentoses were obtained after $18 \mathrm{~h}$, recovering more than $50 \%$ of the initial arabinose without detecting glucose. In order to improve these results, a process in two steps is suggested, recovering all arabinose in liquid phase after a first cycle of $4 \mathrm{~h}$ at $65{ }^{\circ} \mathrm{C}$ and a second one at $80{ }^{\circ} \mathrm{C}$ for $8 \mathrm{~h}(54 \%$ as monomers and the rest as different soluble oligomers, not arabinose detected in the solid phase). At these conditions, the amount of xylose in the solid phase is also negligible, considering this procedure as a good alternative to removal the pentoses from the sawdust, obtaining a pre-treated material with only six-carbon sugars.

\section{Acknowledgments}

The authors would like to acknowledge financial support for this work from the Government of the Principality of Asturias (Contract FC15-GRUPIN14-078). Diego Garcés would also like to thank the Government of the Principality of Asturias for his Ph-D fellowship of the Severo Ochoa Program (BP14-110).

\section{Appendix A. Supplementary data}

Supplementary data associated with this article can be found, in the online version, at http://dx.doi.org/10.1016/j.indcrop.2017.04.027.

\section{References}

Aguedo, M., Vanderghem, C., Goffin, D., Richel, A., Paquot, M., 2013. Fast and high yield recovery of arabinose from destarched wheat bran. Ind. Crops Prod. 43, 318-325.

Alonso, D.M., Bond, J.Q., Dumesic, J.A., 2010. Catalytic conversion of biomass to biofuels. Green Chem. 12, 1493-1513.

Ballina-Casarrubias, L., Saucedo-Acosta, T., McDonald-Pizaña, K., Ruiz-Cuilty, K., Nevárez-Moorillón, G.V., Gutiérrez-Menéndez, N., Torras-Font, C., Chávez-Flores, D.,
González-Sánchez, G., 2015. Organosolv pretreatment for cellulose recovery from sawdust for its ulterior use in membrane synthesis and operation. Desalin. Water Treat. 56, 3626-3639.

Barbosa, M.D.S., Beck, M.J., Fein, J.E., Potts, D., Ingram, L.O., 1992. Efficient fermentation of Pinus sp. acid hydrolysates by an ethanolegenic strain of Escherichia coli. Appl. Environ. Microbiol. 58, 1382-1384.

Capolupo, L., Faraco, V., 2016. Green methods of lignocellulose pretreatment for biorefinery development. Appl. Microbiol. Biotechnol. 100, 9451-9467.

Cara, C., Ruiz, E., Carvalheiro, F., Moura, P., Ballesteros, I., Castro, E., Girio, F., 2012. Production, purification and characterisation of oligosaccharides from olive tree pruning autohydrolysis. Ind. Crop. Prod. 40, 225-231.

Cheng, H., Wang, H., Lv, J., Jiang, M., Lin, S., Deng, Z., 2011. A novel method to prepare L-arabinose from xylose mother liquor by yeast-mediated biopurification. Microb. Cell Fact. 1, 10-43.

Chin, K.L., H'ng, P.S., Go, W.Z., Wong, W.Z., Lim, T.W., Maminski, M., Paridah, M.T., Luqman, A.C., 2013. Optimization of torrefaction conditions for high energy density solid biofuel from oil palm biomass and fast growing species available in Malaysia. Ind. Crops Prod. 49, 7768-7774.

Chum, H.L., Black, S.K., Johnson, D.K., Sarkanen, K.V., Robert, D., 1999. Organosolv pretreatment for enzymatic hydrolysis of poplars: isolation and quantitative structural studies of lignins. Clean Technol. Environ. Policy 1, 187-198.

Deuss, P.J., Barta, K., de Vries, J.G., 2014. Homogeneous catalysis for the conversión of biomass and biomass-derived platform chemicals. Catal. Sci. Technol. 4, 1174-1196.

Dong, S., Bortner, M.J., Roman, M., 2016. Analysis of the sulfuric acid hydrolysis of wood pulp for cellulose nanocrystal production: a central composite design study. Ind. Crops Prod. 93, 76-87.

Ertas, M., Hang, Q., Jameel, H., Chang, H.-m., 2014. Enzymatic hydrolysis of autohydrolyzed wheat straw followed by refining to produce fermentable sugars. Bioresour. Technol. 152, 259-266.

Evtuguin, D., Neto, P., 2007. Recent advances in eucalyptus wood chemistry: structural features through the prism of technological response. In: 3rd International Colloquium on Eucalyptus Pulp. Belo Horizonte, Brazil.

Faba, L., Díaz, E., Ordóñez, S., 2015. Recent developments on the catalytic technologies for the transformation of biomass into biofuels: a patent survey. Renew. Sustain. Energy Rev. 51, 273-287.

Gallezot, P., 2012. Conversion of biomass to selected chemical products. Chem. Soc. Rev. 41, 1538-1558.

Gaur, R., Soam, S., Sharma, S., Gupta, R.P., Bansal, V.R., Kumar, R., Tuli, D.K., 2016. Bench scale dilute acid pretreatment optimization for producing fermentable sugars from cotton stalk and physicochemical characterization. Ind. Crops Prod. 83, $104-112$.

Ghaffar, S.H., Fan, M., McVicar, B., 2015. Bioengineering for utilization and bioconversion of straw biomass into bio-products. Ind. Crops Prod. 77, 262-274.

Gonzales, R.R., Sivagurunathan, P., Kim, S.-H., 2016. Effect of severity on dilute acid pretreatment of lignocellulosic biomass and the following hydrogen fermentation. Int. J. Hydrogen Energy 41, 21678-21684. http://dx.doi.org/10.1016/j.ijhydene. 2016.06.198.

Jiang, L., Li, S., Jian, J., Qiu, J., Wang, P., 2015. Solid-liquid equilibrium of L-arabinose in water + ethanol solvent system from 283.15 to 308.15 K. J. Mol. Liq. 211, 406-410.

Kim, J.W., Mazza, G., 2008. Optimization of phosphoric acid catalyzed fractionation and enzymatic digestibility of flax shives. Ind. Crops Prod. 28, 346-355.

Klinke, H.B., Thomsen, A.B., Ahring, B.K., 2004. Inhibition of ethanol-producing yeast and bacteria by degradation products produced during pre-treatment of biomass. Appl. Microbiol. Biotechnol. 66, 10-26.

Mäki-Arvela, P., Salmi, T., Holmbom, B., Sievers, C., Hoskins, T.J., Agrawal, P.K., Jones, C.W., 2011. Synthesis of sugars by hydrolysis of hemicelluloses-a review. Chem. Rev. 119, 5638-5666.

Marzialetti, T., Valenzuela, M.B., Sievers, C., Hoskins, T.J., Agrawal, P.K., Jones, C.W., 2008. Dilute acid hydrolysis of Loblolly pine: a comprehensive approach. Ind. Eng. Chem. Res. 47, 7131-7140.

Menon, V., Rao, M., 2012. Trends in bioconversion of lignocellulose: biofuels, platform chemicals \& biorefinery concept. Prog. Energy Combust. 38, 522-550.

Moniz, P., Pereira, H., Duarte, L.C., Carvalheiro, F., 2014. Hydrothermal production and gel filtration of xylo-oligosaccharides from rice straw. Ind. Crops Prod. 62, 460-465.

Peng, F., Peng, P., Xy, F., Sun, R.-C., 2012. Fractional purification and bioconversion of hemicelluloses. Biotechnol. Adv. 30, 879-903.

Ragauskas, A.J., Beckham, G.T., Biddy, M.J., Chandra, R., Chen, F., Davis, M.F., Davison, B.H., Dixon, R.A., Gilna, P., Keller, M., Langan, P., Naskar, A.K., Saddler, J.N., Tschaplinski, T.J., Tuskan, G.A., Wyman, C.E., 2014. Lignin valorization: improving lignin processing in the biorefinery. Science 334, 709-719.

Rinaldi, R., Schüth, F., 2009. Acid hydrolysis of cellulose as the entry point into biorefinery schemes. ChemSusChem 2, 1096-1107.

Rivas, S., Raspolli-Galleti, A.M., Antonetti, C., Santos, V., Parajo, J.C., 2016. Sustainable conversion of Pinus pinaster wood into biofuel precursors: a biorefinery approach. Fuel 164, 51-58.

Saha, B.C., 2003. Hemicellulose bioconversion. J. Ind. Microbiol. Biotechnol. 30, 279-291.

Sannigrahi, P., Kim, D.H., Jung, S., Ragauskas, P., 2011. Pseudo-lignin and pretreatment chemistry. Energy Environ. Sci. 4, 1306-1310.

Sidiras, D., Batzias, F., Schroeder, E., Ranjan, R., Tsapatsis, M., 2011. Dye adsorption on autohydrolyzed pine sawdust in batch and fixed-bed systems. Chem. Eng. J. 171, 883-896.

Sluiter, A., Hames, B., Ruiz, R., Scarlata, C., Sluiter, J., Templeton, D., Crocker, D., 2008. Determination of structural carbohydrates and lignin in biomass. Laboratory Analytical Procedure (LAP), NREL/TP-510-42618. National Renewable Energy Laboratory, Golden, Colorado. 
Thygessen, A., Oddershede, J., Liholt, H., Thomsen, A.B., Stahl, K., 2005. On the determination of crystallinity and cellulose content in plant fibres. Cellulose 12 , $563-576$.

Yoon, H.S., Macewam, K., Van Heiningen, A., 2008. Hot-Water Pre-Extraction from Loblolly Pine (Pinus taeda) in an Integrated Forest Products Biorefinery. TAPPIpp.
27-31.

Yu, N., Zhu, Z.-Y., Liu, Y., Zhang, J.-Y., Zhang, Y.-M., 2017. Chromatographic analysis and preparation of L-arabinose from corncob by acid hydrolysis. Ind. Crops Prod. 95, $163-169$. 